\title{
REGULATIONS OF ORPHAN DRUGS IN USA, EU AND INDIA-A COMPARATIVE STUDY
}

\author{
Available online at www.ijdra.com \\ REVIEW ARTICLE \\ ${ }^{1}$ BudhwarVikaas*, ${ }^{1}$ Singh Ajay K, ${ }^{2}$ Choudhary Manjusha \\ ${ }^{1}$ Department of Pharmaceutical Sciences, Maharshi Dayanand University, Rohtak, Haryana, India. \\ ${ }^{2}$ Institute of Pharmaceutical Sciences, Kurukshetra University, Kurukshetra, Haryana, India. \\ *Corresponding Author’s E-mail: vikaasbudhwar@yahoo.com
}

DOI: http://dx.doi.org/10.22270/ijdra.v4i3.187

\begin{abstract}
Orphan drugs are the drugs and natural products used in treatment, diagnosis, or prevention of rare disease. The orphan drug regulation varies in different countries. Initially a guideline (Orphan Drug Act) for orphan drugs has been made in the USA. Exemption from application filing fees, tax credits for clinical research, marketing exclusivity for definite period of time and grant for phase I/II clinical trials are among the benefits given to the manufacturer of orphan drugs. As a result of these benefits number of drugs for the treatment of rare disease has been increased significantly in the last few decades. The orphan drug program can help the pharmaceutical companies in earning profit and recovering their investment even with small patient population in the developed countries. In 2001 a conference was held by the Indian Drugs Manufactures Association (IDMA) where a group of pharmacologists requested the Indian Government to establish the Orphan Drug Act in India. Indian rare disease population depends on developed countries approved orphan drugs because regulation for the orphan drugs has not been made by the Indian government. Developing countries are also feeling they should do something to promote the research and manufacturing of orphan drugs. The scarcity of regulation of orphan drugs adversely affects the economic growth of Indian medicinal industries. The present study reviews the orphan drug regulations in US, EU and India and raises some of the recent issues concerned to their regulation.
\end{abstract}

Keywords: Regulations of orphan drugs, Orphan Drug Act, Orphan drug designation, Orphan drug Status, Orphan drug act amendments, COMP, NORD, OOPD.

\section{INTRODUCTION}

The definition of orphan and rare disease is different in different countries on the bases of the number of patients affected by them. In the United States of America (USA), according to the National Institutes of Health (NIH), 30 million Americans have one of the nearly 7,000 disease that are officially considered "rare" because every of these affect less than 200,000 people in the United States and affect greater than the 200,000 people, but for which recovery of cost of development and market is very challenging. (1) The orphan drug designation depending upon the ratio of the number of patients affected by rare disease which is 7.5 per 10,000 individuals in the USA, 5 per 10,000 individuals in the EU, 4 per 10,000 individuals in Japan, 1 per 10,000 individuals in Australia etc. In the European Union at that time 5,000 to 8,000 different rare diseases affecting $6 \%$ to $8 \%$ population of it. (2) Most rare diseases are genetic; because symptoms do not appear earlier they exist throughout the person's entire life. Some of the rare diseases can be occurring due to allergies or infections (bacterial or viral) or due to proliferative and degenerative causes for example the rare genetic disease Ribose-5phosphate isomerase deficiency has been diagnosed in a single patient only. As the rare disease patient population is very small, rare diseases are generally neglected by the doctors and pharmaceutical companies. Conclusively, acts were made by different countries for regulation of orphan drugs and the introduction of a set of commercial incentives to try to stimulate the production of orphan drug products. (3) The United States was the first country introduced an orphan drug act in 1983, after that number of other countries has followed the program, for example Japan (1993), Singapore (1997), Australia (1998) and the EU (2000). In Europe Union acts were made much later than the USA because it is group of 
28 countries and its capabilities regarding the health is very much dispersed. (4)

The incentives given by governments to the developers and manufacturers of orphan drugs have led to growth of research in this field. A remarkable growth have seen in orphan drug designations, $12 \%$ to 291 in USA and $62 \%$ to 201 in EU from 2013 to 2014. The orphan drug

Table 1: Categories of Orphan Drugs (6) sales were increased $7.7 \%$ to $\$ 97 \mathrm{bn}$ from 2013 to 2014 and it is estimated to grow by $11.7 \%$ per year from 2015 to 2020 to $\$ 178 \mathrm{bn}$. The Orphan drugs sales will be become $20.2 \%$ of worldwide prescription sales of 2020 (excluding generics). (5) The out coming survey of the orphan drugs approved globally is summarized in table 1 .

\begin{tabular}{|c|l|l|l|}
\hline Type & \multicolumn{1}{|c|}{ Detail } & Expected profits & Available medication \\
\hline I & Little / no commercial benefit & Poor & Inadequate \\
\hline II & Commercial benefit & Good to excellent & Inadequate \\
\hline III & $\begin{array}{l}\text { For rare disease that can currently be } \\
\text { treated }\end{array}$ & Variable & Adequate \\
\hline IV & Unprofitable for a common disease & Poor & Inadequate \\
\hline V & Orphan for both rare and common diseases & Variable & Variable \\
\hline
\end{tabular}

Over the period of time, a number of drugs crossed from type I to type III categories. The rare bacterial diseases like Wilson's disease can be treated with antimicrobials, but nowadays it is treated with Penicillamine, zinc \& triethylenetetramine. It is most difficult to find sponsors for type I and type III categories of drug's having pharmaceutical activity but is yet not marketed. If these drugs found to be effective in treating a common disease can become profitable as type $\mathrm{V}$ drugs. The type 2 drugs are profitable but not fulfill the market requirement properly.(6) Details of the USA top 10 selling orphan drugs in 2014 by sales are described in Table 2. Some orphan/rare diseases are listed in the Table 3.

\section{Table 2: USA Top 10 Selling Orphan Drugs in 2014 by Sales (5)}

\begin{tabular}{|c|c|c|c|c|c|c|}
\hline Rank & Product & Generic name & Company & $\begin{array}{l}\text { USA sales } \\
(\$ \mathrm{~m}) 2014\end{array}$ & $\begin{array}{c}\text { Revenues } \\
\text { per patient } \\
2014 \\
\end{array}$ & $\begin{array}{c}\text { No. of } \\
\text { Patient } \\
2014 \\
\end{array}$ \\
\hline 1 & Rituxan & Rituximab & Roche & 3,646 & 54,780 & 66,565 \\
\hline 2 & Copaxone & Glatiramer acetate & $\begin{array}{l}\text { Teva } \\
\text { Pharmaceutical } \\
\text { Industries }\end{array}$ & 3,113 & 33,309 & 93,458 \\
\hline 3 & Revlimid & Benalidomide & Celgene & 2,916 & 112,294 & 25,965 \\
\hline 4 & Gleevec & Imatinib mesylate & Novartis & 2,170 & 90,634 & 2,943 \\
\hline 5 & Avonex & Interferon beta-1a & Biogen & 1,957 & 57,932 & 33,781 \\
\hline 6 & Velcade & Bortezomib & Takeda & 1,396 & 52,838 & 26,414 \\
\hline 7 & Rebif & Interferon beta-1a & Merck KGaA & 1,290 & 61,631 & 20,924 \\
\hline 8 & Alimta & $\begin{array}{l}\text { Pemetrexed } \\
\text { disodium }\end{array}$ & Eli Lilly & 1,230 & 47,378 & 25,951 \\
\hline 9 & Advate & $\begin{array}{ll}\begin{array}{l}\text { Factor } \\
\text { (procoagulant) }\end{array} & \text { VIII } \\
\end{array}$ & Baxalta & 985 & 220,839 & 4,460 \\
\hline 10 & Afinitor & everolimus & Novartis & 805 & 66,390 & 12,125 \\
\hline
\end{tabular}

Table 3: List of Some Orphan Diseases (7)

\begin{tabular}{|l|l|}
\hline Acrocephalosyndactylia & Acrodermatitis \\
\hline Addison Disease & Adie Syndrome \\
\hline
\end{tabular}




\begin{tabular}{|l|l|}
\hline Arthritis, Juvenile Rheumatoid & Asperger Syndrome \\
\hline Bardet-Biedl Syndrome & Barrett Esophagus \\
\hline Beckwith-Wiedemann Syndrome & Behcet Syndrome \\
\hline Carcinoma 256, Walker & Caroli Disease \\
\hline Craniofacial Dysostosis & Creutzfeldt-Jakob Syndrome \\
\hline Crohn Disease & Cushing Syndrome \\
\hline Hirschsprung Disease & Histiocytic Necrotizing Lymphadenitis \\
\hline Histiocytosis, Langerhans-Cell & Hodgkin Disease \\
\hline Inappropriate ADH Syndrome & Intestinal Polyps \\
\hline Kartagener Syndrome & Kearns-Sayre Syndrome \\
\hline Klippel-Feil Syndrome & Klippel-Trenaunay-Weber Syndrome \\
\hline Lafora Disease & Lambert-Eaton Myasthenic Syndrome \\
\hline Landau-Kleffner Syndrome & Langer-Giedion Syndrome \\
\hline Machado-Joseph Disease & Mallory-Weiss Syndrome \\
\hline Marek Disease & Marfan Syndrome \\
\hline Mucopolysaccharidosis IV & Mucopolysaccharidosis VI \\
\hline Multiple Endocrine Neoplasia Type 1 & Munchausen Syndrome by Proxy \\
\hline Neuroaxonal Dystrophies & Neuromyelitis Optica \\
\hline Paralysis & Pelizaeus-Merzbacher Disease \\
\hline Pemphigus, Benign Familial & Penile Induration \\
\hline Rett Syndrome & Reye Syndrome \\
\hline Sandhoff Disease & Sarcoma, Ewing's \\
\hline & \\
\hline &
\end{tabular}

\section{Origin of Orphan Drug Regulations}

After the Kefauver-Harris amendment (1962) was passed it became necessary for all the drugs approved for marketing have to be proven effective and safe through various scientific researches. With increasing the safety of drugs this amendment also increases the cost of development of new medicines. Due to this amendment, pharmaceutical companies could maximize the chances of regaining costs involved in drug development and research and make maximum profits by focusing on developing treatments for common diseases. As a result, rare diseases became 'orphan' because they had poor capacity to give economical profits. Resultantly no treatment was available for rare diseases like Cohn's disease, Hansen's disease.

In late 1970s and early 1980s, the increasing number of patients suffering from rare diseases became major political issue. (8) In 1982 National Organization for Rare Disorders (NORD) and others were formed by coalition of families and supporters of rare disease patients and called for a legislation which enhances the development of orphan drugs. The US government was pressurized by activist groups such as NORD and many others. They got success with passing of the Orphan Drug Act (ODA) by the United State Congress in 1983. The number of the orphan drugs was only thirty eight which had been approved worldwide before 1983 Orphan Drug Act. (9)

By passing with this act, regulatory development path of the orphan drug's approval was remained same as for the other drugs and testing focuses on efficacy, dosing, safety and stability. However, some statistical problems are come in work to continue drug development process. For example, number of the patients suffering from rare a disease may be less than 1000 which minimum requirement for phase III clinical trial but orphan drug regulations considered this fact. Since orphan drugs market is small and unprofitable due to their limited application, government involvement is often essential to encourage a manufacturer to address the requirement for an orphan drug. (10) 


\section{ORPHAN DRUG REGULATION IN US}

The legal status had been given to the orphan drugs in the USA on 4 January 1983 with the passing of an act called the Orphan Drug Act. This act delivers incentives to pharmaceutical companies to develop drugs which are lifesaving and often essential for the patients suffering from rare diseases but had a marginal commercial profit on investment. The Orphan Drug Act is codified in 21 CFR Part 316. A number of amendments were successively passed by congress, which focused on describing the conditions for the drugs to being orphan. The Orphan Drug Act was amended in 1984, 1985, 1988, 1990 and 1992. (4)

\section{Orphan Drug Designation}

The OOPD assess requests for orphan drug designation and when a drug is to be designated it acts as an internal FDA advocate interfacing with the FDA review division to facilitate progress. The OOPD is distinct from the FDA therapeutic review divisions. The review divisions are still answerable for assessing data in terms of risk-versus-benefit considerations and approving drugs for marketing. The OOPD is answerable for assessing, awarding, and watching the progress of orphan drug grants. The ODA make available for granting special status, orphan drug designation, of a product to treat a rare disease or condition upon request of a sponsor. (4) Orphan status does not mean that FDA has given market authorization to the drug. Orphan status and FDA approval of drugs are different things. The approved orphan designation application does not change the standard regulatory requirements and procedure for obtaining marketing approval. Sponsors must prove the safety and efficacy of a compound to treat a rare disease through satisfactory and well-controlled studies. (11)

\section{Orphan Drug Status}

This may be entitled to a drug if it meets the following criteria:

- A drug is not approved earlier

- An approved drug with new orphan indication

- A drug proved clinically superiority over previously approved drug of same category.
Sometimes, orphan status may be granted to a pharmaceutical product if it demonstrates that the subset is medically acceptable for only a subclass of people with a specific disease even when the drug is under development. An example of a medically acceptable subset is the most severely ill patients would use the drug which is so lethal in nature (e.g. Stage IV cancer) but it may produce unknown risks for a less sick patient. (12)

The approval of orphan drugs designation grants the incentives to the pharmaceutical companies in USA such as:

- Marketing exclusivity for Seven-year to the first sponsor getting FDA approval for designated drug

- A Tax credit equal to $50 \%$ of cost involved in clinical research

- Exemption/Waiver in application (filing) fees

- Assistance in the research related to drug development process

- Special grant funding to Orphan Products. (13)

\section{Amendments in Orphan Drug Act}

In 1984, the concept of low incidence was defined for the first time in the USA. A rare disease was defined as that which either affects less than 200,000 people in the USA or more than 200,000 people in the USA without it being possible to earn the price of development and distribution of sales on national territory. The Limit of the prevalence of a rare condition was said to be7, 5 / 10000 . In 1985, the definition of orphan drugs was confined to biologics, medicinal established foods and medical devices, nutraceuticals and parenteral nutrition. In 1988, it was felt that a medicinal product must be a part of the Marketing Authorization application submitted before the application for orphan drug status and it must not have been previously approved following a New Drug Application for the disease or the condition for which the sponsor requests orphan drug status. Orphan drug status: for a disease or a condition. In an amendment in 1992 it was felt that a new orphan drug similar to the existing drug was required to prove its chemical superiority to be approved. More than one sponsor could receive 
designation for the same drug. However, 7 years marketing exclusivity were given to the first sponsor to file the complete NDA. The Competitors were not prohibited from making the drug provide for a different indication during the seven year period of exclusivity. Six and a half million patients are entitled to treatment by orphan drugs in the USA. (14)

\section{ORPHAN DRUG REGULATION IN EUROPEAN UNION}

The first step towards making regulations for orphan drugs in EU was recognition of an emotion that patients suffering from rare conditions should be entitled to the same quality of treatment as other patients. This was recognized and protected in European law with the European regulation 141/2000. (1) Profitable incentives were given in 141/2000 regulation to try to motivate the manufacturers and researchers to develop the orphan medicinal products. These products was intended for the identification, prevention or treatment of lifethreatening or very severe conditions that affect not more than 5 in 10,000 people in the European Union which until then had been largely ignored by the European pharmaceutical industry. In Europe acts were made much later than the USA because it is a group of 28 countries and its capabilities regarding the health is very much scattered. The regulation (EC) No. 141/2000 for orphan drugs was approved on 16 December 1999 by the European Parliament and the Council. The aim was to construct a Committee on Orphan Medicinal Products (COMP) as a subunit of the European Medicines Evaluation Agency (EMEA) which would boost the biotechnological and pharmaceutical industry to discover, develop and market orphan drugs. The liability of this committee is reviewing the applications for orphan designation and assists the Commission to discuss on orphan drugs. (15)

The COMP consists of 28 members nominated by each the European Member State; three members are nominated by the European Commission and three agents of patient associations. The Committee of Propriety Medicinal Products remains in contact with COMP for scientific evaluation of medicinal products and both are accountable for EMEA. The participation of patient association's agents of COMP has been very considerable in the process of emerging new treatments for rare diseases in Europe. (4)

In the EU, small and medium sized enterprises (SMEs) are benefited from incentives which are given in regulation no. 141/2000, but these incentives are reviewed from time to time. Those companies which have EMEA approved designated orphan drug can make profit from incentives such as:

- Procedural assistance is given to the pharmaceutical companies with scientific information for orphan drugs during the research work

- Centralized marketing authorization can be used for drug approval process directly

- Marketing exclusivity for ten years

- Exemptions/discounts in application fees

- Other incentives like national incentives listed in a register which is made by the European Commission. (16)

The fee Reductions are entitled to the orphan medicinal products after 1 February 2009 such as:

- Protocol assistance fee was fully reduced

- Pre-authorization inspections fee was fully reduced, application fee for marketing authorization of new medicinal products was reduced by $50 \%$ for applicants other than small and medium-sized enterprises;

- Application fee for marketing authorization of new medicinal products was fully reduced only for small and medium-sized enterprises;

- Post authorization activities including annual fee was fully reduced only for small and medium sized enterprises after granting a marketing authorization for the first year.

A number of 121 orphan medicines have been approved till 2014 which are benefited the patients suffering from rare diseases. Similarly important, a number of 1295 products have been designated as orphan medicinal products in EU till 2014. (6) The European regulation No. $141 / 2000$ stated that only drugs for human use could be designated as orphan. As a result, it did 
not cover dietary products, nutritional supplements, medical devices and veterinary medicinal products. (15)

\section{ORPHAN DRUG REGULATION IN INDIA}

The regulations for orphan drug manufacturing or marketing have not been made till now in India. Approximately 6,000-8,000rare diseases are found in India, being some of them Wilson Diseases, Leishmaniosis, Norrie Disease, Cystic Fibrosis, Arthrogryposis etc. Most of these diseases are genetic in nature and do not have any treatment. These rare diseases are affecting 72, 611, 605 people in India. The scarcity of regulation of orphan drugs adversely affects the economic growth of Indian medicinal industries. The regulations for orphan drugs have already been made by the different countries like U.S.A, Europe, Japan and Australia. These regulations have special incentives for orphan drugs

Table 4: Rare Diseases list in India (17) manufacturer which enhance the production of orphan medicinal products. These incentives are mentioned regulations for orphan drugs in US and EU. (17)

The condition of rare disease should be addressed by Indian government immediately. A suitable legislation should be made for regulation of orphan drugs. This would help the domestic pharmaceutical and biopharmaceutical industries of India to quickly emerge as a force to include within this significant international space. Indian rare disease population could be benefited from such legislation. This large number of patients suffering with rare diseases should not be left to their own miserable conditions without any consideration and cure. (18) Some rare diseases listed in India are discussed in Table 4. A comparison of orphan drug designation in US and EU is done in table 5.

\begin{tabular}{|c|c|c|}
\hline Disease & Per 100,000 & Total Indian Population \\
\hline Acatalasmia & 3 & 36,000 \\
\hline Acromegly & 5 & 60,000 \\
\hline Alkaptornuria & 0.3 & 3,600 \\
\hline Alpa-1 antritrypsin & 25 & 300,000 \\
\hline Grave disease & 50 & 600,000 \\
\hline Parkinson disease & 15 & 180,000 \\
\hline
\end{tabular}

Table 5: (US \& EU Orphan Designations per Year 2010-2014) (5)

\begin{tabular}{|l|c|c|c|c|}
\hline \multirow{2}{*}{ Year } & \multicolumn{2}{|c|}{ Designations per Year } & \multicolumn{2}{c|}{ Growth per Year } \\
\cline { 2 - 5 } & USA & EU & USA & EU \\
\hline 2010 & 195 & 130 & $+18 \%$ & $+19 \%$ \\
\hline 2011 & 202 & 108 & $+4 \%$ & $-17 \%$ \\
\hline 2012 & 190 & 149 & $-6 \%$ & $+38 \%$ \\
\hline 2013 & 260 & 124 & $+37 \%$ & $-17 \%$ \\
\hline 2014 & 291 & 201 & $+12 \%$ & $+62 \%$ \\
\hline
\end{tabular}

Is sighted in Table 5, However, as not even a regarding Indian market. A comparison of single orphan drug has been approved in India till date, no such comparison can be made incentives in US, EU and India is shown in Table 6.

Table 6: Incentives of Orphan Drug Legislation in US, EU and India $(4,19,20)$

\begin{tabular}{|l|c|c|c|c|c|}
\hline \multirow{2}{*}{ Items } & \multicolumn{2}{|c|}{ US } & \multicolumn{2}{c|}{ EU } & India \\
\cline { 2 - 6 } & Orphan & Other drugs & Orphan & Other drugs & Other drugs \\
\hline Market exclusivity & 7 years ${ }^{\mathrm{d}}$ & 5 year $\mathrm{e} / 3$ years & 10 years ${ }^{\mathrm{a}, \mathrm{b}}$ & $8^{\mathrm{g}}+2^{\mathrm{h}}+1^{\mathrm{i}}$ & $7-8^{\mathrm{j}}$ years \\
\hline $\begin{array}{l}\text { Protocol assistance } \\
\text { and follow-up }\end{array}$ & Yes & No & Yes & No & No \\
\hline
\end{tabular}




\begin{tabular}{|l|c|c|c|c|c|}
\hline $\begin{array}{l}\text { Reduced /waived } \\
\text { regulatory fees }\end{array}$ & Yes & No & Yes & No \\
\hline $\begin{array}{l}\text { Tax credit on } \\
\text { clinical trials }\end{array}$ & Yes & No & No & No & No \\
\hline $\begin{array}{l}\text { Specific subsidies } \\
\text { for clinical trials }\end{array}$ & Yes & No & No & No & No \\
\hline
\end{tabular}

In sighted in table no.6 there is no regulation for orphan drugs in India. a- If pediatric development included then an extra two years exclusivity is also added, b- If the product is sufficiently profitable then exclusivity may reduce to 6 years, c- Besides the various national grants EU funding is available for rare disease, d- An additional 6 month of pediatric exclusivity for successful studies, e-New chemical entities, f-Existing chemical entities for new indications, g-8 years data exclusivity starting from the date of authorization by European Commission: before that, generic applications may not be filed during this period, h- 2 years marketing protection, generic applications may not be approved during this period, i- Additional 1 year exclusivity for new indication(s) if it establishes a vital clinical benefit, $\mathbf{j}$-Time remaining after drug approval from patent life.

\section{CONCLUSION}

The orphan drug regulations made by different countries have proven as promoters in development of orphan drugs. The orphan drug regulation in the US and the EU has been successful in providing treatments to the patients with rare diseases. The orphan drug designations have increased drastically in the last few years. However, India in spite of having very large number of patients with rare diseases which can become a huge market for domestic pharmaceutical companies is lagging behind. Government of India should therefore make legislation for regulation of orphan drugs and give some incentives to the pharmaceutical companies which could benefit both patients and pharmaceutical industries.

\section{ACKNOWLEDGEMENT}

I acknowledge my co-authors for their sincere and dedicated efforts to help me to review and compile the facts and information which helped me to frame this article.

\section{CONFLICTS OF INTEREST}

The authors declare that there are no conflicts of interest.

\section{REFERENCES}

1. Singh MK, Sharma PK, Sharma N. Orphan Drug Development: A Brief Review. Journal of Pharmacy Research. 2011; 4(8):2645-7.

2. European Medicine Agency [Internet]. Medicines for Rare Diseases: 3-5; 2016 [cited 2016 Apr 13]. Available from:

http://www.ema.europa.eu/ema/index.jsp?curl=pages/ special_topics/general/general_content_000034.jsp

3. Engel PA, Bagal S, Broback M, Boice N. The Need for Stronger Educational Initiatives for Physicians. Journal of Rare Disorder. 2013; 1(2):1-15.

4. Hall AK and Carlson MR. The Current Status of Orphan Drug Development in Europe and the US. International Journal of Rare Disorder Research. 2014; 3(1): 1-7.

5. Orphan Drug Report [Internet]. Welcome to the Evaluate Pharma Orphan Drug Report. [updated 2015 oct 30; cited 2016 Apr 3] Available from: http://www.evaluategroup.Com/public/reports/Evalua tePharma-Orphan-Drug-Report-2015.

6. Kataria MK, Garg M, Anand V, Bilandi A, Kukkar V, Bhandari A. An Insight on Regulations Governing Orphan Diseases and Drugs. Research Journal of Pharmaceutical, Biological and Chemical Sciences. 2011; 2(3): 373-84.

7. Addison A, Alagille D, Amyotrophic S, Sclerosis L, Hyperplasia A. List of Rare Diseases. Drug News and Perspectives. 1996; 9(8): 4-6.

8. Davis H and Smith J. Orphan Drug Law Matures into Medical Mainstay. International Journal of Rare Disorder Research. 1999; 33(3): 11-16.

9. Kesselheim AS. Innovation and the Orphan Drug Act 1983-2009. Regulatory and Clinical Characteristics of Approved Orphan Drugs. 2015; (DC):1-12.

10. Rare Diseases: Common Issues in Drug Development [Internet]. Guidance for Industry Rare Diseases; 2015 Aug [cited 2016 Apr 10]. Available from: http://www.fda.gov/downloads/Drugs/GuidanceCom plianceRegulatoryInformation/Guidances/UCM4584 85.pdf

11. McNeilly EK. Designating an Orphan Product: Drug and Biological Products - Orphan Drug Regulations 
[Internet]. Regulatory History 283745; 2014 [cited 2016 Apr 16] Available from:

http://www.fda.gov/ForIndustry/DevelopingProductsf orRareDiseasesConditions/HowtoapplyforOrphanPro ductDesignation/ucm356481.htm

12. Sharma A, Jacob A, Tandon M, Kumar D. Orphan drug: Development Trends and strategies. Journal of Pharmacy and Bio-Allied Sciences. 2010; 2(4):290-9.

13. Seoane VE, Rodriguez MR, Szeinbach SL, Visaria J, Incentives for orphan drug research and development in the United States, Orphanet Journal of Rare Disease, 2008; 4(3):33.

14. Orphanet -The portal for rare diseases and orphan drugs [Internet]. Orphan drugs in the United States of America; 2016 [cited 2016 Apr 26] Available from: http://www.orpha.net/consor/cgibin/Education_AboutOrphanDrugs.php?lng=EN\&sta page=ST_EDUCATION_EDUCATION_ABOUTOR PHANDRUGS_USA.

15. European Union. Commission Regulation (EC) No $141 / 2000$ of the European Parliament. Official Journal of European Union [Internet]. 2000 [cited 2016April 30]; L18:1-5. Available from: http://ec.europa.eu/health/files/eudralex/vol1/reg_2000_141/reg_2000_141_en.pdf

16. European Union. Commission Regulation (EC) No 2003/C 178/02 of the European Parliament. Official Journal of the European Communities [Internet]. 2003 [cited2016 May 4]; L178:1-7. Available from: http://eur-lex.europa.eu/LexUriServ/LexUriServ.do? uri=OJ:C:2003:178:0002:0008:EN:PDF

17. Gajra BB and Limbachiya S. Absence of Regulations for Orphan Drugs in India: Ignorance of the Government [Internet]. 2015 [cited 2016 May 7] Available from: https://aapsblog.aaps.org/2015/05/13/absence-ofregulations-for-orphan-drugs-in-india-ignorance-ofthe-government/

18. Divya VC and Sathasivasubramanian S. Submandibular Sialolithiasis - A report of two cases. The Journal of Medical Research. 2015; 1(1): 05-07.

19. Hathaway C, Manthei J, Scherer CZ. Food and Drug Law Institute. 2009; (3).

20. Janodia MD, Chauhan A, Hakak SM, Sreedhar D, Ligade VS, Udupa N. Data Exclusivity Provisions in India: Impact on Public Health. Journal of Intellectual Property Rights. 2008;13 (5):442-6. 